\title{
Resposta de brócolis, couve-flor e repolho à adubação com boro em solo arenoso
}

\author{
Luiz Carlos Pizetta ${ }^{1,2}$; Manoel Evaristo Ferreira ${ }^{1}$; Mara Cristina P. da Cruz ${ }^{1}$; José Carlos Barbosa ${ }^{3}$ \\ ${ }^{1}$ UNESP, FCAV, Depto. Solos e Adubos, Via de Acesso Prof. Paulo Donato Castellane, s/no, 14884-900 Jaboticabal-SP; E-mail: \\ evaristo@fcav.unesp.br; ${ }^{2}$ Doutorando em Agronomia (Produção Vegetal) da UNESP, FCAV; ${ }^{3}$ Departamento de Ciências Exatas.
}

\section{RESUMO}

Foram avaliados em condições de campo, em solo arenoso, com baixo teor de boro, os efeitos da adubação com cinco doses de boro $\left(0 ; 2 ; 4 ; 6\right.$ e $8 \mathrm{~kg} \mathrm{ha}^{-1}$ de $\mathrm{B}$ na forma de bórax $)$ na produção de brócolis, couve-flor e repolho. O experimento obedeceu a um esquema fatorial com delineamento experimental de blocos ao acaso com três repetições. As adubações orgânica e química, inclusive o bórax, foram feitas no sulco antes do transplantio das mudas e a colheita foi feita entre 63 e 93 dias após o transplantio. A produtividade de brócolis variou de 16,9 a 20,5 $\mathrm{tha}^{-1}$; a de couve-flor de 21,6 a 29,6 $\mathrm{t} \mathrm{ha}^{-1} \mathrm{e}$ a de repolho de 40,5 a 46,4 tha-1. $\mathrm{O}$ aumento observado na produtividade de brócolis e de repolho foi linear e o efeito das doses de boro na produtividade de couve-flor foi quadrático, sendo necessários $5,1 \mathrm{~kg}$ $\mathrm{ha}^{-1}$ de $\mathrm{B}$ para atingir a produtividade máxima de $30 \mathrm{t} \mathrm{ha}^{-1}$. Brócolis e repolho mostraram-se menos sensíveis do que a couve-flor tanto à deficiência quanto ao excesso de boro. No caso da couve-flor, com a aplicação de $2 \mathrm{~kg} \mathrm{ha}^{-1}$ ou de $6 \mathrm{~kg} \mathrm{ha}^{-1}$ de $\mathrm{B}$ houve significativa perda de qualidade do produto.

Palavras-chave: Brassica oleracea var. italica, B. oleracea var. botrytis, $B$. oleracea var. capitata, micronutriente, diagnose foliar, produtividade.

\begin{abstract}
Response of boron fertilization on broccoli, cauliflower and cabbage planted in sandy soil

The effects of boron fertilization on yield of broccoli, cauliflower and cabbage were evaluated through a field experiment carried out on a sandy soil low in available boron. Five boron levels $(0 ; 2 ; 4 ; 6$; and $8 \mathrm{~kg} \mathrm{ha}^{-1} \mathrm{~B}$ as borax) were applied in broccoli, cauliflower and cabbage using a factorial scheme and a randomized block design with three replicates. Organic manure and chemical fertilizers, including borax, were applied in the planting furrow before seedlings transplant and plants were harvested 63 to 93 days after planting date. The yield intervals obtained with broccoli, cauliflower and cabbage varied according to the following intervals: 16.9 to $20.5 \mathrm{t}$ $\mathrm{ha}^{-1}, 21.6$ to $29.6 \mathrm{t} \mathrm{ha}^{-1}$ and 40.5 to $46.3 \mathrm{t} \mathrm{ha}^{-1}$, respectively. The increase in production observed in broccoli and cabbage yield was linear with boron levels and the boron effect on cauliflower yield was quadratic. For maximum cauliflower yield (30 $\left.\mathrm{tha}^{-1}\right) 5,1 \mathrm{~kg} \mathrm{ha}^{-}$ ${ }^{1}$ of B were necessary. Broccoli and cabbage were less sensible than cauliflower to boron deficiency and toxicity. Quality of the curds decreased when 2 or $6 \mathrm{~kg} \mathrm{ha}^{-1} \mathrm{~B}$ were applied in cauliflower fertilization.
\end{abstract}

Keywords: Brassica oleracea var. italica, B. oleracea var. botrytis, B. oleracea var. capitata, micronutrient, leaf diagnosis, yield.

(Recebido para publicação em 18 de dezembro de 2003 e aceito em 17 de novembro de 2004)

$\mathrm{O}$ boro, além de ser nutriente de plantas, é essencial para o homem e atua no metabolismo de nutrientes e de substratos energéticos, no funcionamento do cérebro e na performance psicomotora e cognitiva (Nielsen, 1997). A ingestão diária de $\mathrm{B}$ por uma pessoa adulta deve ser de 1 a $13 \mathrm{mg}$ e as suas principais fontes são as frutas, os grãos de leguminosas e as hortaliças (WHO/ FAO/IAEA, 1996, citados por Nielsen, 1997). Entre as hortaliças ricas em B estão o rabanete, a beterraba, a cenoura e as brássicas e, no grupo destas últimas, o brócolis, o repolho e a couveflor são as mais consumidas.

O limite entre deficiência e toxicidade de boro nas plantas é estreito e ele pode ser extremamente tóxico para algumas espécies em concentrações pouco acima da considerada ótima (Gupta, 1983).
A deficiência de boro nas brássicas resulta em coloração escura na parte central do caule, cabeças pequenas, pouco compactas e com partes escuras e, na couve-flor, coloração bronzeada na inflorescência (Filgueira, 1982).

De maneira geral, brócolis, couveflor e repolho respondem à adubação com boro e a intensidade da resposta é, normalmente, associada ao teor original deste nutriente no solo, ao tipo de solo e à cultivar. Produções de repolho na ordem de 44,5 (100\%), 43,2 (97\%) e 37,8 t ha-1 (85\%) foram obtidas por Álvares et al. (1985), em Latossolo Vermelho-Amarelo, textura argilosa, com $0,38 \mathrm{mg} \mathrm{kg}^{-1} \mathrm{de}$ $\mathrm{B}$ extraído com água quente, com aplicação de, respectivamente, 8,26; 5,75 e $2,05 \mathrm{~kg} \mathrm{ha}^{-1}$ de B. No tratamento que não recebeu adubação com $B$ foram produzidos repolhos com cabeças frouxas e a compacidade das cabeças aumentou com as doses de B. Em Latossolo VermelhoEscuro, textura média, com 0,30 mg dm${ }^{3} \mathrm{de} \mathrm{B}$, em $\mathrm{BaCl}_{2}$, na presença e ausência de calagem, as maiores produções de repolho foram obtidas com $4 \mathrm{~kg} \mathrm{ha}^{-1}$ de B. Nesse caso, as concentrações de B no solo e nas folhas aumentaram com a adição de B e produção relativa de cabeças igual a $90 \%$ foi associada a $20 \mathrm{mg} \mathrm{kg}^{-1}$ de B nas folhas e $0,53 \mathrm{mg} \mathrm{dm}^{-3}$ de B no solo (Coutinho et al., 1999).

Em solo barro argiloso com $0,21 \mathrm{mg}$ $\mathrm{kg}^{-1}$ de B extraído com água quente a couve-flor não respondeu à aplicação de $\mathrm{B}$, e em solo barro arenoso, com 0,07 $\mathrm{mg} \mathrm{kg}^{-1} \mathrm{de} \mathrm{B}$, alcançou produção máxima de $12 \mathrm{t} \mathrm{ha}^{-1}$ com 4,4 kg ha ${ }^{-1}$ de B (Batal et al., 1997).

A produção de brócolis, cultivares Bacus e Futura, em Latossolo Verme- 
lho-Escuro, textura média, com 1,07 mg $\mathrm{kg}^{-1}$ de B, não foi afetada pela adubação com B, mas a das cultivares Early Dawn e Galaxy diminuiu com a adição de 2,16 $\mathrm{kg} \mathrm{ha}^{-1}$. Isto indica que as últimas cultivares são mais sensíveis a excesso de $\mathrm{B}$ do que as primeiras. Os teores de B nas folhas aumentaram com as doses aplicadas, exceto na cv. Galaxy, na qual diminuiu (Mello et al., 1997).

Trani et al. (1996) recomendam para o estado de São Paulo 3 a $4 \mathrm{~kg} \mathrm{ha}^{-1}$ de B para brócolis, couve-flor e repolho, sem levar em consideração as características do solo, mais três aplicações foliares durante o ciclo com solução contendo 1 $\mathrm{g} \mathrm{L}^{-1}$ de ácido bórico. As classes de teores usadas para interpretação e avaliação da disponibilidade de boro no solo, atualmente em uso no estado de São Paulo (Raij et al., 1996), são gerais, e podem estar ou não adequadas às culturas mais exigentes ou aos diferentes tipos de solo.

O objetivo deste trabalho foi avaliar o efeito da adubação com boro na produção de brócolis, couve-flor e repolho em solo arenoso.

\section{MATERIAL E MÉTODOS}

O experimento foi instalado no município de Santa Rita do Passa Quatro (SP), cujas coordenadas geográficas são $21^{\circ} 42^{\prime} 26^{\prime \prime}$ de Latitude Sul e $47^{\circ} 28^{\prime} 46^{\prime \prime}$ de Longitude Oeste, altitude de 759 metros.

A caracterização química da área foi feita em amostra de solo coletada na profundidade de 0 a $0,2 \mathrm{~m}$, que resultou da mistura de 20 amostras simples. Os resultados obtidos foram: $\mathrm{P}$ resina $=13$ mg dm${ }^{-3} ;$ M.O. $=14 \mathrm{~g} \mathrm{dm}^{-3} ; \mathrm{pH} \mathrm{em} \mathrm{CaCl}^{2}$ $=5,1 ; \mathrm{K}^{+}=3,0 \mathrm{mmol}_{\mathrm{c}} \mathrm{dm}^{-3} ; \mathrm{Ca}^{2+}=18$ mmol $\mathrm{dm}^{-3} ; \mathrm{Mg}^{2+}=8 \mathrm{mmol} \mathrm{dm}^{-3} ; \mathrm{H}+$ $\mathrm{A}^{1}=20 \mathrm{mmol}_{\mathrm{c}} \mathrm{dm}^{-3} ; \mathrm{SB}=29 \mathrm{mmol}$ $\mathrm{dm}^{-3}$; CTC $=49 \mathrm{mmol} \mathrm{dm}^{-3}$ e V $=59 \%$ (Raij et al., 1987). O B, 0,15 mg dm ${ }^{-3}$, foi extraído com solução de $\mathrm{BaCl}_{2} 1,25$ $\mathrm{g} \mathrm{L}^{-1}$ em forno de microondas (Abreu et al., 1994); o Cu, 2,5 mg dm ${ }^{-3}$; o Fe, 72 $\mathrm{mg} \mathrm{dm}{ }^{-3}$; o $\mathrm{Mn}, 38,2 \mathrm{mg} \mathrm{dm}^{-3}$ e o $\mathrm{Zn}$, $2,6 \mathrm{mg} \mathrm{dm}^{-3}$, foram extraídos com solução de DTPA 0,005 $\mathrm{mol} \mathrm{L}^{-1}$ (Lindsay e Norvell, 1978) e o S-SO ${ }_{4}^{2-}, 4 \mathrm{mg} \mathrm{dm}{ }^{-3}$, com solução de $\mathrm{Ca}\left(\mathrm{H}_{2} \mathrm{PO}_{4}\right)_{2}$,, $01 \mathrm{~mol} \mathrm{~L}^{-1}$ (Cantarella e Prochnow, 2001). A análi- se textural do solo revelou: 200; 120 ; $680 \mathrm{~g} \mathrm{~kg}^{-1}$ de argila, silte e areia, respectivamente.

O local do experimento recebeu calcário dolomítico em área total, para elevar o índice de saturação por bases a $80 \%$, conforme recomendação de Trani et al. (1996). A incorporação foi feita 120 dias antes do plantio com uma aração na profundidade de 0 a 0,2 m, seguida de uma gradagem.

O delineamento experimental foi em blocos ao acaso, em esquema fatorial, associando cinco doses de B e três cultivares de brássicas, com três repetições, totalizando 45 parcelas. As doses de boro foram $0 ; 2 ; 4 ; 6$ e $8 \mathrm{~kg} \mathrm{ha}^{-1}$ e as cultivares de brássicas, o brócolis (Brassica oleracea var. italica, híbrido Legacy), a couve-flor (Brassica oleracea var. botrytis, híbrido Júlia) e o repolho (Brassica oleracea var. capitata, híbrido Kenzan).

Cada parcela foi constituída por sete linhas de 5,5 m de comprimento, com espaçamento nas entrelinhas de $0,80 \mathrm{~m}$ e entre plantas de $0,50 \mathrm{~m}$, totalizando 77 plantas; a área útil foi formada pelas três linhas centrais, desprezando-se duas plantas de cada extremidade (21 plantas na área útil).

Nos sulcos de plantio, a $15 \mathrm{~cm}$ de profundidade, foram aplicadas $10 \mathrm{tha}^{-1}$ (peso seco) de vermicomposto de esterco de curral; boro, na forma de bórax, segundo os tratamentos; e 60; 600; 180 e $72 \mathrm{~kg} \mathrm{ha}^{-1}$ de $\mathrm{N}, \mathrm{P}_{2} \mathrm{O}_{5}, \mathrm{~K}_{2} \mathrm{O}$ e S, respectivamente, nas formas de sulfato de amônio, superfosfato triplo e cloreto de potássio. A adubação N, P, K foi feita de acordo com a recomendação de Trani et al. (1996) e os adubos foram incorporados levemente com enxada.

A análise do vermicomposto, segundo métodos descritos em Kiehl (1985) e em Tedesco et al. (1985), revelou a seguinte composição (base em peso seco): $\mathrm{pH}$ em $\mathrm{CaCl}_{2}=6,0 ; \mathrm{C}=226 \mathrm{~g} \mathrm{~kg}^{-1}$; $\mathrm{N}=16 \mathrm{~g} \mathrm{~kg}^{-1} ; \mathrm{P}=4 \mathrm{~g} \mathrm{~kg}^{-1} ; \mathrm{K}=5 \mathrm{~g} \mathrm{~kg}^{-1} ; \mathrm{Ca}$ $=7 \mathrm{~g} \mathrm{~kg}^{-1} ; \mathrm{Mg}=3 \mathrm{~g} \mathrm{~kg}^{-1} ; \mathrm{B}=12 \mathrm{mg} \mathrm{kg}^{-1}$; $\mathrm{Cu}=81 \mathrm{mg} \mathrm{kg}^{-1} ; \mathrm{Fe}=52677 \mathrm{mg} \mathrm{kg}^{-1}$; $\mathrm{Mn}=423 \mathrm{mg} \mathrm{kg}^{-1} \mathrm{e} \mathrm{Zn}=185 \mathrm{mg} \mathrm{kg}^{-1}$. Em 06/07/2001, as brássicas foram semeadas em bandejas de 128 células com substrato organo-mineral, marca comercial Plantmax ${ }^{\circledR}$ hortaliças, mantidas em estufa e irrigadas diaria- mente. Aos 34 dias, quando as mudas atingiram quatro a seis folhas definitivas, foram transplantadas no campo.

As adubações de cobertura, com uréia e cloreto de potássio (175 e $90 \mathrm{~kg}$ $\mathrm{ha}^{-1}$ de $\mathrm{N}$ e $\mathrm{K}_{2} \mathrm{O}$, respectivamente), segundo Trani et al. (1996), foram aplicadas em quatro vezes, a cada 15 dias, iniciando-se 20 dias após o transplantio (DAT). Na primeira adubação foi feita também uma pulverização foliar com solução contendo $0,5 \mathrm{~g} \mathrm{~L}^{-1}$ de molibdato de amônio, cerca de $400 \mathrm{~L} \mathrm{ha}^{-1}$ de calda. Durante a condução do experimento foram feitas irrigações e capinas conforme a necessidade.

Foram coletadas as folhas recémdesenvolvidas na formação da cabeça das plantas de brócolis (aos 37 DAT) e de couve-flor (aos 44 DAT) e as folhas envoltórias no início da formação da cabeça das plantas de repolho (aos 54 DAT), conforme recomendação de Trani e Raij (1996). As amostras de folha foram lavadas, secas e moídas para determinação de B segundo Bataglia et al. (1983).

A colheita do brócolis, da couve-flor e do repolho começou aos 65 DAT e se estendeu por 30 dias. Foram avaliadas as três cultivares e anotados o peso e o diâmetro. No caso da couve-flor foram avaliados os defeitos das 21 plantas centrais, segundo CEAGESP (2000). Após a colheita foi feita amostragem de solo nas linhas de plantio, parcela por parcela.

Os efeitos da adubação com boro nas características das plantas e na produção foram avaliados por meio de análise de variância pelo teste $\mathrm{F}$ e, nos casos em que houve significância das doses de boro, foi usada análise de regressão polinomial.

\section{RESULTADOS E DISCUSSÃO}

Houve efeitos significativos de cultivares e da aplicação de boro na produtividade $(\mathrm{F}=682,33 * *$ e $\mathrm{F}=12,32 * *$, respectivamente) e no número de cabeças $\left(\mathrm{F}=7,85^{* *}\right.$ e $\mathrm{F}=4,11^{* *}$, respectivamente) e da interação dos dois fatores na produtividade $(\mathrm{F}=2,51 *)$. A aplicação de $\mathrm{B}$ propiciou aumento linear na produtividade de brócolis e de repolho e efeito quadrático na de couve-flor (Figura 1).

A adubação com vermicomposto com $12 \mathrm{mg} \mathrm{kg}^{-1}$ de B foi responsável por 
Resposta de brócolis, couve-flor e repolho à adubação com boro em solo arenoso

Tabela 1. Número de cabeças de brócolis, repolho e couve-flor em função de doses de boro. Santa Rita do Passa Quatro (SP), UNESP, 2001.

\begin{tabular}{|c|c|c|c|c|c|c|c|c|c|}
\hline \multirow{3}{*}{ Boro (kg ha ${ }^{-1}$ ) } & Brócolis & Repolho & \multicolumn{7}{|c|}{ Couve-flor } \\
\hline & \multirow{2}{*}{\multicolumn{2}{|c|}{$C M^{1}\left(n^{0} h^{-1}\right)$}} & \multirow{2}{*}{ total } & \multicolumn{2}{|c|}{ com podridão } & \multicolumn{2}{|c|}{ com deformação } & \multirow{2}{*}{$\begin{array}{c}\mathrm{CM}^{1} \\
\mathrm{n}^{\circ} \mathrm{ha}^{-1}\end{array}$} & \multirow{2}{*}{ tipo ${ }^{2}$} \\
\hline & & & & $\mathrm{n}^{\circ} \mathrm{ha}^{-1}$ & $\%$ & $\mathrm{n}^{\circ} \mathrm{ha}^{-1}$ & $\%$ & & \\
\hline$\overline{0}$ & 23016 & 24206 & 25000 & 4365 & 17 & 3968 & 16 & 20635 & FE \\
\hline 2 & 24206 & 24603 & 24206 & 1587 & 07 & 0807 & 03 & 22619 & FE \\
\hline 4 & 24603 & 24603 & 24603 & 0000 & 00 & 0781 & 03 & 24603 & $\mathrm{Cl}$ \\
\hline 6 & 24206 & 24206 & 24603 & 0794 & 03 & 1992 & 08 & 23809 & C III \\
\hline 8 & 24206 & 24603 & 23810 & 0794 & 03 & 0794 & 03 & 23016 & C III \\
\hline
\end{tabular}

${ }^{1}$ cabeças comercializáveis

${ }^{2}$ Classificação segundo CEAGESP (2000), FE = fora de especificação; CI = categoria 1 ; CIII = categoria 3.

levar a cada parcela, independentemente do tratamento, $120 \mathrm{~g} \mathrm{ha}^{-1} \mathrm{de} \mathrm{B}$, o que é uma quantidade muito pequena quando comparada aos 2, 4, 6 ou $8 \mathrm{~kg} \mathrm{ha}^{-1}$ aplicados na forma de bórax. Prova disso está no fato de que na testemunha (que também recebeu os $120 \mathrm{~g} \mathrm{ha}^{-1} \mathrm{de}$ B) apareceram sintomas visuais de deficiência na couve-flor e, como já comentado, houve efeito do B adicionado como bórax na produção das três cultivares.

As produtividades de brócolis e de repolho obtidas neste experimento estão dentro da faixa citada por Trani e Raij (1996), respectivamente, 10 a 30 e 30 a $60 \mathrm{t} \mathrm{ha}^{-1}$, e a de couve-flor está bem acima das 8 a 16 t ha $^{-1}$ citadas pelos autores. Esta diferença de comportamento, em parte, deve-se a cultivares mais produtivas desenvolvidas nos últimos anos.

$\mathrm{O}$ brócolis apresentou, em relação à testemunha $\left(0,15 \mathrm{mg} \mathrm{dm}^{-3}\right.$ de B no solo extraído com $\mathrm{BaCl}_{2}$ ) um incremento de $18 \%$ na produtividade com aplicação de $8 \mathrm{~kg} \mathrm{ha}^{-1}$ de B. Em ensaios de campo, em solos com 0,$46 ; 0,49 ; 0,34$ e 0,48 $\mathrm{mg} \mathrm{kg}^{-1}$ de B extraído com água quente, Gupta e Cutcliffe (1973) não obtiveram respostas na produtividade de brócolis com aplicação de até $4,48 \mathrm{~kg} \mathrm{ha}^{-1}$ de B. Mello et al. (1997), em solo contendo $1,07 \mathrm{mg} \mathrm{kg}^{-1}$ de B, empregando as doses 0 e $2,16 \mathrm{~kg} \mathrm{ha}^{-1}$, não observaram efeito do $\mathrm{B}$ na produtividade de brócolis das cultivares Bacus e Futura, e houve diminuição na produção das cultivares Early Dawn e Galaxy.

Plantas de brócolis com caule oco ocorreram de forma generalizada em todos os tratamentos. Esta anomalia tem sido associada à deficiência de boro e Mello et al. (1997) relataram diminuição de ocorrência de ocamento das has-

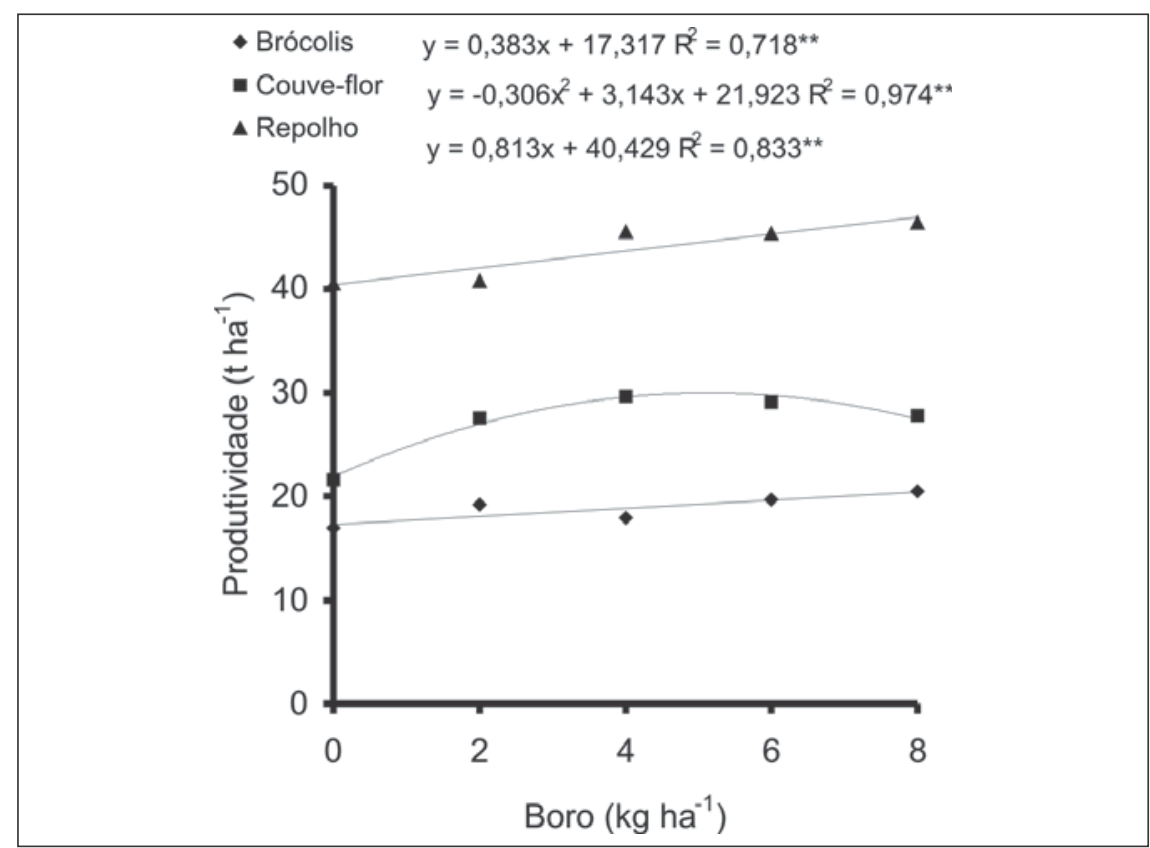

Figura 1. Produtividade de brócolis, couve-flor e repolho em função de doses de boro. Santa Rita do Passa Quatro (SP), UNESP, 2001.

tes em brócolis com a aplicação de boro. Por outro lado, Shattuck e Shelp (1987), do mesmo modo como foi observado no presente estudo, não obtiveram relação entre caule oco em brócolis cv. Stolto e Emperor e concentração de boro nos tecidos ou no solo, e argumentaram que fatores adicionais como cultivar e condições ambientais podem ser de maior importância que aspectos nutricionais.

A produtividade máxima de couveflor foi $30 \mathrm{t} \mathrm{ha}^{-1}$, obtida com $5,1 \mathrm{~kg} \mathrm{ha}^{-1}$ de B (Figura 1). Com 4 kg ha ${ }^{-1}$ de B, a couve-flor apresentou produtividade $35 \%$ maior do que a do tratamento sem B. No tratamento sem B houve uma grande porcentagem de cabeças de couve-flor com podridão e deformadas (cabeças frouxas), o que afetou a produção final (Tabela 1). Algumas plantas apresentaram coloração castanha e cavida- des nas partes internas do caule. Com a dose $2 \mathrm{~kg} \mathrm{ha}^{-1}$ de $\mathrm{B}$ também ocorreram anomalias nas cabeças, mas com menor intensidade. Com as doses 6 e $8 \mathrm{~kg} \mathrm{ha}^{-1}$ de $\mathrm{B}$ ocorreu morte de plantas, com diminuição de 2 e $6 \%$ na produtividade, respectivamente, indicando efeito fitotóxico. Gupta e Cutcliffe (1973) obtiveram a produtividade máxima de couve-flor $\left(27,33 \mathrm{t} \mathrm{ha}^{-1}\right)$ com 2,24 $\mathrm{kg} \mathrm{ha}^{-1}$ de $\mathrm{B}$, que foi reduzida para $24,45 \mathrm{tha}^{-1}$ com a aplicação de 4,48 $\mathrm{kg} \mathrm{ha}^{-1}$, sem que ocorressem sintomas visuais de toxicidade de boro. Kotur e Kumar (1989), em experimento de campo em solo areno-argiloso que continha $0,1 \mathrm{mg}$ $\mathrm{kg}^{-1}$ de B em água quente, verificaram aumento na produção de couve-flor de $0,4 \mathrm{t} \mathrm{ha}^{-1}$ na testemunha para $9,15 \mathrm{tha}^{-1}$ com aplicação de $1,6 \mathrm{~kg} \mathrm{ha}^{-1}$ de B. Com doses maiores do que $1,6 \mathrm{~kg} \mathrm{ha}^{-1}$ de $\mathrm{B}$ 
Tabela 2. Distribuição de cabeças de brócolis, couve-flor e repolho por classes de diâmetro ou de peso. Santa Rita do Passa Quatro (SP), UNESP, 2001.

\begin{tabular}{|c|c|c|c|c|c|c|c|c|c|c|}
\hline \multirow{3}{*}{$\begin{array}{l}\text { Boro } \\
\text { kg ha- }^{-1}\end{array}$} & \multicolumn{2}{|c|}{ Cabeça } & \multicolumn{8}{|c|}{ Classes } \\
\hline & diâmetro & peso & 1 & 2 & 3 & 4 & 5 & 6 & 7 & 8 \\
\hline & $\mathrm{cm}$ & kg & \multicolumn{8}{|c|}{$\%$ de cabeças } \\
\hline \multicolumn{11}{|c|}{ Brócolis $^{1}$} \\
\hline$\overline{0}$ & 18,43 & 0,74 & 5 & 24 & 62 & 9 & 0 & & & \\
\hline 2 & 19,89 & 0,80 & 0 & 8 & 62 & 25 & 5 & & & \\
\hline 4 & 19,20 & 0,72 & 0 & 24 & 56 & 15 & 5 & & & \\
\hline 6 & 19,77 & 0,80 & 0 & 18 & 47 & 32 & 3 & & & \\
\hline 8 & 20,37 & 0,84 & 0 & 10 & 54 & 33 & 3 & & & \\
\hline \multicolumn{11}{|c|}{ Couve-flor ${ }^{2}$} \\
\hline 0 & 17,61 & 1,05 & 0 & 3 & 12 & 27 & 27 & 31 & 0 & 0 \\
\hline 2 & 18,66 & 1,23 & 0 & 0 & 0 & 21 & 30 & 35 & 12 & 2 \\
\hline 4 & 18,36 & 1,20 & 0 & 0 & 1 & 23 & 40 & 21 & 10 & 5 \\
\hline 6 & 18,17 & 1,22 & 0 & 0 & 7 & 18 & 40 & 25 & 8 & 1 \\
\hline 8 & 18,44 & 1,19 & 0 & 1 & 0 & 16 & 40 & 29 & 14 & 0 \\
\hline \multicolumn{11}{|c|}{ Repolho $^{3}$} \\
\hline 0 & 18,66 & 1,67 & 20 & 80 & 0 & & & & & \\
\hline 2 & 19,24 & 1,66 & 13 & 87 & 0 & & & & & \\
\hline 4 & 20,03 & 1,78 & 11 & 89 & 0 & & & & & \\
\hline 6 & 19,97 & 1,87 & 3 & 97 & 0 & & & & & \\
\hline 8 & 20,30 & 1,89 & 2 & 97 & 2 & & & & & \\
\hline
\end{tabular}

${ }^{1}$ Sugestão para classificação de brócolis, com base no diâmetro em cm: $1=<15,0$ (tamanho muito pequeno); $2=15,0$ a $<18,0$ (tamanho pequeno); $3=18,0$ a $<21,0$ (tamanho médio); $4=21,0$ a $<24,0$ (tamanho grande) e $5=\geq 24,0$ (tamanho muito grande).

${ }^{2}$ Classes segundo CEAGESP (2000), para cabeça com diâmetro em $\mathrm{cm}: 1=<10,0 ; 2=10,0$ a $<13,0 ; 3=13,0$ a $<15,0 ; 4=15,0$ a $<17,0 ; 5=17,0$ a $<19,0 ; 6=19,0$ a $<21,0 ; 7=21,0$ a $<23,0 ;$ e $8 \geq 23,0$.

${ }^{3}$ Classes de repolho com base no peso da cabeça comercializada no CEASA-Ribeirão Preto, em $\mathrm{kg}: 1=<1,50 ; 2=1,50 \mathrm{a}<2,50 ; 3=\geq 2,50$.

os autores constataram diminuição da produção.

A produtividade de repolho foi, em média, $16 \%$ maior no tratamento com 8 $\mathrm{kg} \mathrm{ha}^{-1}$ de B do que a do tratamento sem B. Gupta e Cutcliffe (1984), em solos com teores variando entre 0,3 a $0,5 \mathrm{mg}$ $\mathrm{kg}^{-1}$ de B em água quente, não obtiveram aumento de produtividade de repolho com a aplicação de até $8,8 \mathrm{~kg} \mathrm{ha}^{-1}$ de B. Álvares et al. (1985), Carneiro et al. (1995) e Coutinho et al. (1999), respectivamente, obtiveram produtividade máxima de repolho com a aplicação de 7,$18 ; 10,1$; e $4 \mathrm{~kg} \mathrm{ha}^{-1}$ de B. No primeiro caso, o teor de boro no solo era de $0,38 \mathrm{mg} \mathrm{dm}^{-3}$ (água quente), no segundo $0,05 \mathrm{mg} \mathrm{dm}^{-3}$ (água quente) e no último $0,30 \mathrm{mg} \mathrm{dm}^{-3}\left(\mathrm{BaCl}_{2} 1,25 \mathrm{~g} \mathrm{~L}^{-1}\right)$, e as produções máximas foram respectivamente $44,5 \mathrm{t} \mathrm{ha}^{-1} ; 38,78 \mathrm{tha}^{-1} \mathrm{e} 46,8 \mathrm{t}$ $\mathrm{ha}^{-1}$. Os dois primeiros autores trabalharam com repolho 'Matsukaze' e, o últi- tou em cabeças atrofiadas e bastante afetadas pela podridão causada por fitotoxicidade.

Com base em defeitos, que incluem podridão e deformação (CEAGESP, 2000), as cabeças de couve-flor foram classificadas de acordo com o tipo (Tabela 1). A produção dos tratamentos sem adição de B e com $2 \mathrm{~kg} \mathrm{ha}^{-1}$ de B ficou fora de especificação (Tabela 1), pois havia mais de $5 \%$ de cabeças com podridão. Desta forma, verifica-se um menor número de cabeças comercializáveis nestes dois tratamentos, o que resulta em menor remuneração ao agricultor. Com aplicação de 4 $\mathrm{kg} \mathrm{ha}^{-1}$ de B não ocorreu podridão e apenas $3 \%$ das cabeças estavam deformadas, sendo produzidas cabeças de couve-flor na categoria I. Esta foi a melhor classificação obtida neste experimento, que resultaria em remuneração mais vantajosa. Nas doses de 6 e $8 \mathrm{~kg} \mathrm{ha}^{-1}$ de $\mathrm{B}$, foi obtida a mesma porcentagem de cabeças com podridão (3\%), e $8 \%$ e $3 \%$ de cabeças deformadas, respectivamente, e a couve-flor foi classificada na categoria III, que também representa produto de menor valor comercial.

O estudo de regressão entre diâmetro da inflorescência de brócolis (Tabela 2) e doses de boro foi linear ( $\mathrm{y}=$ $\left.0,188 \mathrm{x}+18,840, \mathrm{R}^{2}=0,64 * *\right)$. Do mesmo modo, o diâmetro e o peso das cabeças de repolho (Tabela 2) aumentaram linearmente com as doses de boro segundo as equações $\mathrm{y}=0,200 \mathrm{x}+$ $18,837\left(\mathrm{R}^{2}=0,89 * *\right)$ e $\mathrm{y}=0,032 \mathrm{x}+$ $1,645\left(\mathrm{R}^{2}=0,90^{* *}\right)$, respectivamente. Para o diâmetro da cabeça de couve-flor, a análise de regressão não foi significativa. Com doses de $8 \mathrm{~kg} \mathrm{ha}^{-1}$ de B no brócolis e repolho e de $2 \mathrm{~kg} \mathrm{ha}^{-1}$ de $\mathrm{B}$ na couve-flor, os aumentos observados nos diâmetros das cabeças foram de $11 \%$, $6 \%$ e $9 \%$, respectivamente.

Ao se analisar a produção de couveflor nas classes usadas pela CEAGESP (2000), observa-se maiores porcentagens de cabeças dentro das classes 4; 5 e 6. Em todas as doses de B aplicadas no solo, estas três classes somaram 83 a $86 \%$ das cabeças (Tabela 2). Houve maior concentração de cabeças na classe 5 (diâmetro de $17 \mathrm{a}<19 \mathrm{~cm}$ ) com aplicação de 4 a $8 \mathrm{~kg} \mathrm{ha}^{-1}$ de B. 
A distribuição de cabeças de repolho nas classes usadas pela CEAGESP ${ }^{1}$ é feita em três classes de peso (Tabela 2). No tratamento sem B, 20\% das cabeças de repolho estão na classe 1 e $80 \%$ na classe 2. Com a adição de 6 e $8 \mathrm{~kg} \mathrm{ha}^{-1}$ de $\mathrm{B}$ diminuiu o número de cabeças na classe 1 e aumentou na classe 2 , atingindo $97 \%$ de cabeças nesta última classe. O aumento de cabeças na classe 2 , com 8 $\mathrm{kg} \mathrm{ha}^{-1}$, foi de $21 \%$ em relação ao tratamento sem B. Bergamin (2003), com aplicação de $8 \mathrm{~kg} \mathrm{ha}^{-1}$ de B, obteve uma redução de $60 \%$ de cabeças de repolho na classe $2(1,5$ a $2,5 \mathrm{~kg})$, e aumento de $181 \%$ na classe $3(\geq 2,50 \mathrm{~kg})$, em relação ao tratamento sem B.

Na literatura não foi encontrada classificação para diâmetro da inflorescência de brócolis e tentativa foi feita considerando cinco classes baseadas na comercialização usada na CEAGESP $^{1}$, apresentada na Tabela 2. Nas doses 0; 2 e $4 \mathrm{~kg} \mathrm{ha}^{-1}$ de B foram produzidas $95 \%$ das cabeças de brócolis nas classes 2, 3 e 4, com diâmetro de $15 \mathrm{a}<24 \mathrm{~cm}$ e nas doses 6 e $8 \mathrm{~kg} \mathrm{ha}^{-1}$ a produção de cabeças atingiu 97\% nessas três classes. As classes 1 e 5 (tamanho muito pequeno e muito grande, diâmetros $<15 \mathrm{~cm}$ e $\geq 24 \mathrm{~cm}$, respectivamente) apresentam menor valor comercial.

Os teores de boro na folha de brócolis variaram de 32 a $62 \mathrm{mg} \mathrm{kg}^{-1}$ e aumentaram linearmente com as doses de boro. Para o repolho foi obtido o mesmo efeito das doses de boro e a variação de teores observada foi de 33 a 81 $\mathrm{mg} \mathrm{kg}{ }^{-1}$. Na couve-flor a variação observada foi de 18 a $40 \mathrm{mg} \mathrm{kg}^{-1}$ e a regressão com as doses de boro foi quadrática (Figura 2). Geraldson et al. (1973) determinaram teores de B de 30 a $100 \mathrm{mg} \mathrm{kg}^{-1}$ em brócolis e 30 a $60 \mathrm{mg}$ $\mathrm{kg}^{-1}$ em repolho. Furlani et al. (1978) obtiveram teores de B iguais a $23 \mathrm{mg}$ $\mathrm{kg}^{-1}$ em brócolis, $56 \mathrm{mg} \mathrm{kg}^{-1}$ em couveflor e $29 \mathrm{mg} \mathrm{kg}^{-1}$ em repolho. Gupta e Cutcliffe (1984) relataram variação de 41 a $132 \mathrm{mg} \mathrm{kg}^{-1}$ de B em folha de repolho 'Houston Evergreen' com aplicação de $8,8 \mathrm{~kg} \mathrm{ha}^{-1}$ de $\mathrm{B}$ e os teores adequados nas folhas foram entre 16 e $24 \mathrm{mg}$

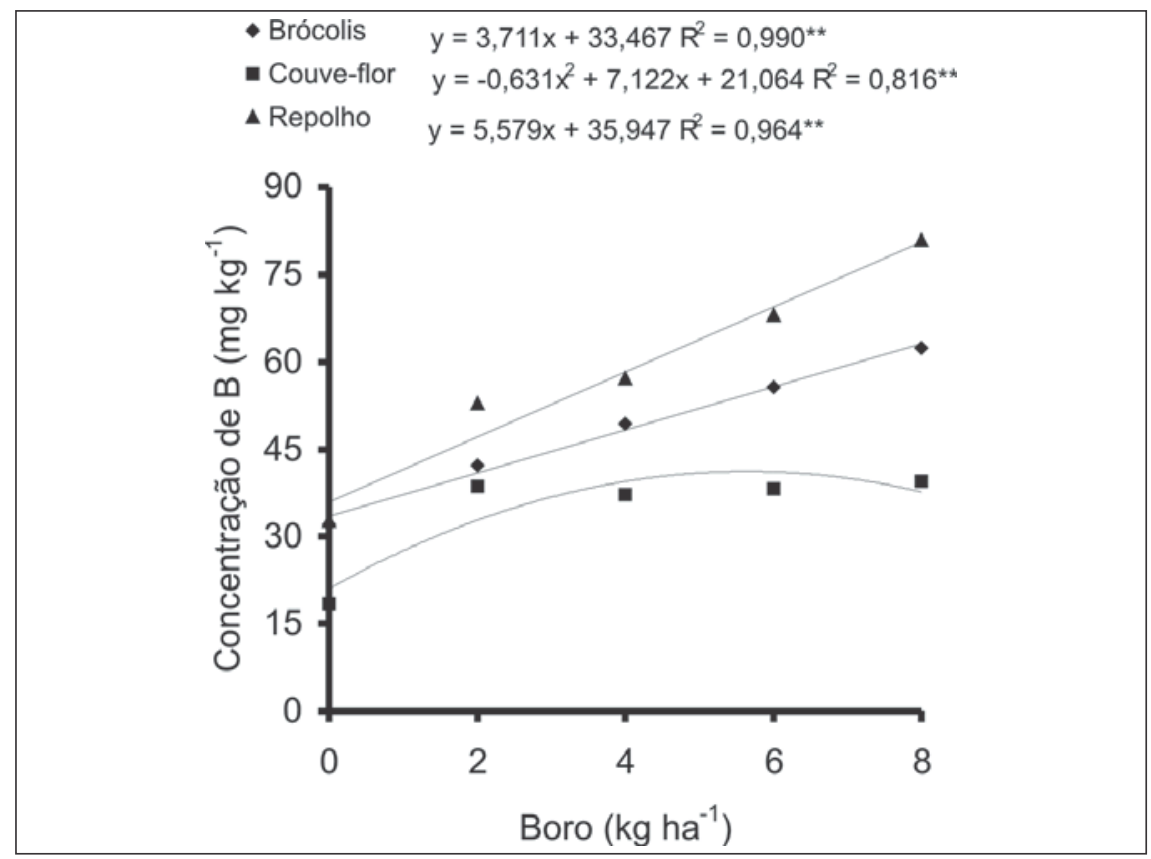

Figura 2. Concentração de B nas folhas de brócolis, couve-flor e repolho em função das doses de boro. Santa Rita do Passa Quatro (SP), UNESP, 2001.

$\mathrm{kg}^{-1}$. Estes mesmos autores citam a faixa entre 13 e $70 \mathrm{mg} \mathrm{kg}^{-1}$ como teor foliar adequado de $\mathrm{B}$ para brócolis e entre $8 \mathrm{e}$ $97 \mathrm{mg} \mathrm{kg}^{-1}$ para couve-flor, na fase de formação de cabeças. Álvares et al. (1985) observaram concentrações entre 20 e $40 \mathrm{mg} \mathrm{kg}^{-1}$ com aplicação de até 10 $\mathrm{kg} \mathrm{ha}^{-1}$ de B em repolho 'Matsukaze' e obtiveram valores de 24,2 $\mathrm{mg} \mathrm{kg}^{-1}$ e 38,2 $\mathrm{mg} \mathrm{kg}^{-1}$ de B nas folhas, quando atingiram produções de 37,8 e 44,5 $\mathrm{tha}^{-1}$, respectivamente. Coutinho et al. (1999) verificaram que uma produção relativa de cabeças de repolho híbrido Fuyutoyo igual a $90 \%$ esteve associada a teores iguais a $20 \mathrm{mg} \mathrm{kg}^{-1}$ nas folhas.

Assim, repolho e brócolis acumulam mais boro nos tecidos do que a couve-flor, o que concorda com os resultados apresentados por Francois (1986). Segundo o autor, embora brócolis e couve-flor apresentem alta exigência em boro, para cada $1 \mathrm{mg} \mathrm{L}^{-1} \mathrm{de}$ $\mathrm{B}$ adicionado na água de irrigação os teores de B nas folhas de couve-flor e brócolis aumentaram, respectivamente, 8 e $47 \mathrm{mg} \mathrm{kg}^{-1}$.

Essas diferenças entre brócolis, couve-flor e repolho estão, de certo modo, contempladas nas classes de teores de boro considerados por Trani e Raij (1996): 30 a $100 \mathrm{mg} \mathrm{kg}^{-1}$ para brócolis; 30 a $80 \mathrm{mg} \mathrm{kg}^{-1}$ para couve-flor e $25 \mathrm{a}$ $75 \mathrm{mg} \mathrm{kg}^{-1}$ para repolho. No caso da couve-flor, no tratamento que não recebeu boro e houve manifestação de deficiência acentuada, o teor nas folhas foi de $18 \mathrm{mg} \mathrm{kg}^{-1}$. Com a aplicação de $2 \mathrm{~kg}$ $\mathrm{ha}^{-1}$ de B o teor aumentou para $39 \mathrm{mg}$ $\mathrm{kg}^{-1}$ e a partir daí se manteve praticamente constante com o aumento das doses de boro. Assim, considerando que com $2 \mathrm{~kg} \mathrm{ha}^{-1}$ de boro ocorreram ainda muitas perdas por podridões associadas à deficiência de boro (Tabela 1), e que as folhas apresentavam teor adequado, e que com a aplicação de 6 e $8 \mathrm{~kg} \mathrm{ha}^{-1}$ de $\mathrm{B}$ o teor nas folhas se manteve adequado mas houve perda de plantas por toxicidade, a análise foliar não se mostrou ferramenta suficientemente sensível para diagnóstico de carência leve e excesso de boro para a couve-flor 'Júlia'.

Em relação à produtividade e teor de B na folha, a análise de regressão foi linear crescente para as três brássicas (y $=0,100 \mathrm{x}+14,000, \mathrm{R}^{2}=0,43^{*}$ para

\footnotetext{
${ }^{1}$ CEAGESP - Companhia de Entrepostos e Armazéns Gerais de São Paulo, Ribeirão Preto. Comunicação Pessoal (2001).
} 
brócolis; $\mathrm{y}=0,330 \mathrm{x}+15,777, \mathrm{R}^{2}=$ $0,66 * *$ para couve-flor e $\mathrm{y}=0,124 \mathrm{x}+$ $36,485, \mathrm{R}^{2}=0,46^{* *}$ para repolho). Para a produtividade em função do teor de boro no solo extraído com solução de $\mathrm{BaCl}_{2} 1,25 \mathrm{~g} \mathrm{~L}^{-1}$, a correlação foi linear para brócolis e repolho $(\mathrm{y}=1,728 \mathrm{x}+$ $16,736, \mathrm{R}^{2}=0,507 * *$ e $\mathrm{y}=4,043 \mathrm{x}+$ $39,792, \mathrm{R}^{2}=0,421^{* *}$, respectivamente) e quadrática para couve-flor $(\mathrm{y}=$ $3,495 \mathrm{x}^{2}+12,029 \mathrm{x}+19,438, \mathrm{R}^{2}=$ $0,703 * *)$. Assim, a máxima produção de couve-flor foi relacionada a $1,72 \mathrm{mg}$ $\mathrm{dm}^{-3}$ de B no solo.

De acordo com os resultados obtidos, brócolis e repolho respondem à adubação com boro, mas são menos sensíveis à deficiência e ao excesso do que a couve-flor. A couve-flor, por sua vez, mostrou-se muito sensível à deficiência e à toxicidade, de modo que, em solo arenoso com baixo teor de boro a produtividade máxima estimada em 30 t ha $^{-1}$ foi obtida com aproximadamente $5 \mathrm{~kg} \mathrm{ha}^{-1}$ do nutriente, e com a aplicação de $2 \mathrm{~kg}$ ha $^{-1}$ ou de $6 \mathrm{~kg} \mathrm{ha}^{-1}$ de B houve significativa perda de qualidade do produto. Assim, para couve-flor, confirmou-se a afirmação de que existe um estreito intervalo entre a deficiência e o excesso de boro para as plantas.

\section{LITERATURA CITADA}

ABREU, C.A.; ABREU, M.F.; RAIJ, B. VAN; BATAGLIA, O.C.; ANDRADE, J.C. Extraction of boron from soil by microwave heating for ICP-AES determination. Communications in Soil Science and Plant Analysis, v.25, p.3321-3333, 1994.

ÁLVARES, M.C.; OLIVEIRA, S.A; MATTOS, J.K.A.; MESQUITA FILHO, M.V. Resposta de repolho à adubação com bórax. Horticultura Brasileira, Brasília, v.3, p.18-21, 1985.

BATAGLIA, O.C.; FURLANI, A.M.C.; TEIXEIRA, J.P.F.; FURLANI, P.R.; GALLO, J.R. Métodos de análise química de plantas. Campinas: Instituto Agronômico, 1983. 48 p. (Boletim Técnico, 78)
BATAL， K.M.; GRANBERRY， D.M.; MULLINISC, J.B.G. Nitrogen, magnesium, and boron applications affect cauliflower yield, curd mass, and hollow stem disorder. Hortscience, v.32, n.1, p.75-78, 1997.

BERGAMIN, L.G. Resposta de repolho à aplicação de boro associada à utilização de adubo orgânico. 2003. 38 f. (Tese mestrado) - UNESP, FCAV, Jaboticabal.

CANTARELLA, H.; PROCHNOW, L.I. Determinação de sulfato em solos. IN: RAIJ, B. VAN; ANDRADE, J.C.; CANTARELLA, H.; QUAGGIO, J.A. (Ed.) Análise química para avaliação da fertilidade de solos tropicais. Campinas: Instituto Agronômico, 2001. p.225-230.

CARNEIRO, I.F.; ALMEIDA NETO, J.X.; NAVES, R.V.; CHAVES, L.J. Efeito de diferentes níveis de boro, na presença e ausência de matéria orgânica, na cultura do repolho (Brassica oleracea var. capitata). Horticultura Brasileira, Brasília, v.3, p.65, 1985. (resumo)

CEAGESP. Classificação de couve-flor; Centro de Qualidade em Horticultura, 2000. (Folder).

COUTINHO, E.L.M.; NATALE, W.; NISHIKAWA, M.A.N.; CASTELLANE, P.D. Efeitos da calagem e da adubação com boro na produção e no estado nutricional das plantas de repolho. In: CONGRESSO BRASILEIRO DE CIÊNCIA DO SOLO, 27, 1999, Brasília. Resumos. Brasília: SBCS, 1999. CD-Rom.

FILGUEIRA, F.A.R. Manual de olericultura: cultura e comercialização de hortaliças. São Paulo: Editora Agronômica Ceres, 1982. v.2, 357 p.

FRANCOIS, L.E. Effect of excess boron on broccoli, cauliflower, and radish. Journal of American Society Horticultural Science, v.111, p.494-498, 1986.

FURLANI, C.M.; FURLANI, P.R.; BATAGLIA, O.C.; HIROCE, R.; GALLO, J.R. Composição mineral de diversas hortaliças. Bragantia, Campinas, v.37, p.33-37, 1978.

GERALDSON, C.M.; KLACAN, G.R.; LORENZ, O.A. Plant analysis as an aim in fertilizing vegetable crops. In: WALSH, L.M.; BEATON, J. D. (Ed.) Soil testing and plant analysis. Madison: Soil Science Society of America, 1973. p.365-380.

GUPTA, U.C. Boron deficiency and toxicity symptoms for several crops as related to tissue boron levels. Journal of Plant Nutrition, v.6, p.387-395, 1983.

GUPTA, U.C.; CUTCLIFFE, J.A. Boron nutrition of broccoli, brussels sprouts, and cauliflower grown on Prince Edward Island soils. Canadian
Journal of Soil Science, v.53, p.275-279, 1973. GUPTA, U.C.; CUTCLIFFE, J.A. Effects of applied and residual boron on the nutrition of cabbage and field beans. Canadian Journal Soil Science, v.64, p.571-576, 1984.

KIEHL, E.J. Fertilizantes orgânicos. São Paulo: Editora Agronômica Ceres, 1985. 492 p.

KOTUR, S.C.; KUMAR, S. Response of cauliflower (Brassica oleracea convar botrytis var botrytis) to boron in Chhotanagpur region. Indian Journal of Agricultural Science, v.59, p.640-644, 1989.

LINDSAY, W.L; NORVELL, W.A. Development of a DTPA soil test for zinc, iron, manganese, and copper. Soil Science Society America Journal, v.42, p.421-428, 1978.

MELLO, S.C.; CASTELLANE, P.D.; CORTÊZ, G.E.P. Influência do boro no desenvolvimento e na produtividade de cultivares de brócoli (Brassica oleracea var. italica). Científica, Jaboticabal, v.25, n.2, p.269-277, 1997.

NIELSEN, F.H. Boron in human and animal nutrition. Plant and Soil, v.193, p.199-208, 1997. RAIJ, B. VAN; QUAGGIO, J.A.; CANTARELLA H.; FERREIRA, M.E.; LOPES, A.S.; BATAGLIA, O.C. Análise química de solo para fins de fertilidade. Campinas: Fundação Cargill, 1987. $170 \mathrm{p}$.

RAIJ, B. VAN; CANTARELLA, H.; QUAGGIO, J.A.; FURLANI, A.M.C. (Ed.) Recomendações de adubação e calagem para o Estado de São Paulo. Campinas: Instituto Agronômico/Fundação IAC, 1996. p.12. (Boletim Técnico, 100)

SHATTUCK, V.I.; SHELP, B.J. Effect of boron nutrition on hollow stem in broccoli (Brassica oleracea var. italica). Canadian Journal of Plant Science, v.67, p.1221-1225, 1987.

TEDESCO, M.J.; VOLKSWEISS, S.J.; BOHNEN, H. Análises de solo, plantas e outros materiais. Porto Alegre: Faculdade de Agronomia/ UFRGS, 1985. (Boletim Técnico, 5)

TRANI, P.E.; RAIJ, B. VAN Hortaliças. In: RAIJ, B.; CANTARELla, H.; QUAGGIO, J.A.; FURLANI, A.M.C. (Ed.) Recomendações de adubação e calagem para o Estado de São Paulo. Campinas: Instituto Agronômico/Fundação IAC, 1996. p.157-164. (Boletim Técnico, 100)

TRANI, P.E.; PASSOS, F.A.; AZEVEDO, J.A.; TAVARES, M. Brócolos, couve-flor e repolho. In: RAIJ, B. VAN; CANTARELLA, H.; QUAGGIO, J.A.; FURLANI, A.M.C. (Ed.) Recomendações de adubação e calagem para o Estado de São Paulo. Campinas: Instituto Agronômico/Fundação IAC, 1996. p.175. (Boletim Técnico, 100) 